\title{
Modeling Customer Relationship Management Pattern Using Human Factors Approach in the Hospitals of Tehran University of Medical Sciences
}

\author{
Sedigheh Taghavi, ${ }^{1}$ Leila Riahi, ${ }^{1,}{ }^{*}$ Amir Ashkan Nasiripour, ${ }^{1}$ and Katayoun Jahangiri ${ }^{2}$ \\ ${ }^{1}$ Department of Health Services Administration, Science and Research Branch, Islamic Azad University, Tehran, Iran \\ ${ }^{2}$ Department of Health in Disaster and Emergencies, School of Health, Safety and Environment, Shahid Beheshti University of Medical Sciences, Tehran, Iran \\ "Corresponding author: Leila Riahi, Department of Health Services Administration, Science and Research Branch, Islamic Azad University, Tehran, Iran. Tel: +98-44868542, Fax: \\ +98-44868542, E-mail: l.riahi@srbiau.ac.ir
}

Received 2016 February 16; Revised 2016 May 10; Accepted 2016 June 10.

\begin{abstract}
Background: Studies show that the transformation of organizations to become customer- centric businesses is one of the strategic issues today.

Objectives: The present study aimed to design a customer relationship management protocol with the approach of human resources.

Methods: This was a mixed method (qualitative and quantitative) research that has been conducted on hospital administrators (n $=290$ ) based on the structural equations by exploratory and confirmatory factor analysis. The software used for data analysis were Smart PLS version 2 and SPSS version 22. Constructions and items were selected through repeated scale according to the opinions of scientists, experts and comparatives studies. Confirmation of the researcher-made questionnaire reliability was performed using the judgments of experts and their reliability. The reliability upon Cronbach's Alpha was 0.935.

Results: Factors including employee satisfaction, organizational culture, communication management, organizational commitment, empowerment, teamwork, organizational structure, management change and organizational mission influenced the implementation of customer relationship management. Factor load of employee satisfaction $(0.802)$ had the highest impact while the organizational mission had the least impact (0.587). Goodness of Fit of the model was 0.566 .

Conclusions: Human resources management has an important role in the implementation of customer relationship management. Therefore, hospital administrators should provide cultural context and support staff to encourage customer-oriented culture.
\end{abstract}

Keywords: Customer Relationship Management, Customer Orientation, Hospital, Healthcare

\section{Background}

In the new business processes, it is important to achieve customer satisfaction as part of the organizational goals. Transformation of the organizations in order to obtain customer- oriented satisfaction is one of the hottest strategic issues in the literature. In order to successfully implement this strategy, Customer Relationship Management (CRM) is essential (1). Nowadays despite the past, the presence of customer relationship management system in the organization is not considered as a competitive advantage, but it has transformed into a requirement, which if not applied, it will not be possible to achieve organizational goals (2).

Dergi (as noted in Schurter's and Towers's book) believes that customer relationship management has three modes with different importance weights: $45 \%$ of success of CRM depends on the top management of the organization, $40 \%$ on the employees of an organization, and $15 \%$ on the software and hardware. Thus, $85 \%$ of the success of
CRM depends on the human resources, including senior managers, who are the custodians of the philosophy and strategy and the pioneer of the culture, and $45 \%$ of success also depends on the employees, who should take steps with worthy thought, word, deeds subscriptions and collective skills in regards to CRM (3).

Different definitions of customer relationship management have been provided. Thomson believed that a group counts the customer relationship management strategy, as the technology, while some others consider it as the process and the other group consider it as management information systems (4).

Liou's perspective: CRM is a business strategy and develops a customer- centric approach across the organization (5). The terms of CRM with its modern concept emerged in the 1990s and it was developed as a part of a business strategy to select and manage the most valuable customer relationships. Customer Relationship Management requires a customer-oriented philosophy and a cul- 
ture to support effective marketing, sales and after-sales processes in the organization (6).

One of the most influential factors in the implementation of customer relationship management is human resources, which needs human resource management (7). Implementation of the CRM process requires developing a change in the organization, structure, and the business processes. For this purpose, organizational structure, organizational commitment and human resource management are considered (8). An appropriate organization structure needs to create working teams, customer-focused teams, coordinator teams and multitasking teams, which require coordination and integration between different parts of the organization (9). The problem that is considered after the modeling of the organization structure is the commission in the whole structure (10).

Although the successful implementation of CRM factors including strategy, employees, technology and processes are important, human resources have an integral role in building customer relationships. The most difficult part to become a customer-focused organization is not the modern technology, but it is the employees (11). In service organizations, the source of competitive advantage is the quality of service and manpower providing the service (12). In order to underpin the competitive feature of the organization in the current competitive conditions, four key components are considered: culture (attitudes and behaviors in the organization), processes, systems (with special emphasis on communication), innovation and creativity. The organization's culture should be changed to become customer oriented with commitment to the customer, and processes, systems and organizational policies should be changed (13). Gandhi (as noted in Tehrani's book) is the most important supervisor of our activities; the customer is not dependent on us, and we are dependent upon the customer. However, the clients are not an elusive goal, and they are the goal of all of our customers. Customers are not considered as outsiders in our organization, and they are a part of our organization. We do not favor customers through the provision of customer services, but they give us an opportunity to continue to work (14).

Becoming customer-oriented in the health system has three pillars: the attention paid to patient satisfaction, the quality of services, and the attention to employee satisfaction. Staff is the major factor in ensuring customer satisfaction and requires knowledge and skills to work with clients and to meet their needs and expectations. The second pillar is attention to the quality of services. The comprehensive attitude to services quality will provide the needs and expectations of the customers. Total quality focuses on customer quality, technical quality and service quality. The third pillar is attention to customer satisfaction. The continuous assessment of needs and customer satisfaction, and its continuous analysis and interventions are based on the results of the analysis, and the success and progress of health organizations (15).

Nowadays, health organizations require higher standards of CRM than other industries (16). Therefore, the identification and prioritization of factors affecting the implementation of CRM can play a decisive role in the implementation process and the establishment of this species for a system. Previous researches indicate the above concept.

According to the perspective of Habidin, the health service providers should provide better services for their patients under competitive pressure. The use of CRM as a strategy to support quality improvement services can impact the organizational performance. This research studied "the relationship between CRM, development of the quality of service and the performance through SEM in Malaysia's healthcare industry" (17). It also emphasized on friends and colleague's duties (2014) to increase organizational performance, considering customer-orientation, and customer needs and expectations. The mentioned study was conducted "in the context of the integration of CRM and improvement of its performance through the correlation" (18).

Orina by the analysis of organizational factors affecting customer relationship management in the banking system in Burma believed that successful implementation of CRM depends on the promotion of customer-oriented culture, top management support, staff knowledge, organizational structure and satisfaction of employees (19). Furthermore, the aspects of organizational structure (formalization, complexity and concentration) are important in enhancing customer satisfaction. Azizzadeh in a research titled "communication of organizational structure and its effect on the CRM in the bank" mentioned the role of organizational structure and its impact on the referred customer (20).

A study by Yaghoubi and colleagues titled "Designing a model of CRM in the hospitals of Medical Sciences through SEM" demonstrated that the implementation of CRM improves the quality of service, while it can also be used to identify and prioritize the customer, absorb the customer, provide customer interaction (communication), diversity of services, and customer retention (21).

Akgün et al. considered the role of management in elevating the function of Turkey's banking system in customer relationship (22). Moreover, Gbadeyan considered the implementation of customer relationship in hospital settings as a means of enhancing the quality of services and patients' satisfaction (23). Tafti had the opinion that 
the effective factors in customer service management include management change, planning, strategy, and information technology (24).

\section{Objectives}

Several studies have been conducted in the field of CRM around the world studied from various aspects, but there is less research in terms of the human dimension. The aim of this study was to design a CRM with the approach of human factors in hospitals of Tehran University of Medical Sciences.

\section{Methods}

Objective-wise, the present study was descriptiveanalytical, and qualitative- and quantitative-based in implementation.

Constructions and items were selected through repeated scale, according to the opinions of scientists, experts and comparatives studies. In this study, the questionnaire was a data collection tool that contained 46 questions. The questionnaire had seven dimensions including:

1) Organizational culture

2) Employee satisfaction

3) Empowerment

4) Communication management

5) Change management

6) Organizational structure

7) Organizational commitment

The questionnaire was scored by the five-item Likert scale $(1=$ very low to $5=$ very high $)$.

In order to confirm the validity of the questionnaire, it was distributed among ten university professors and ten executives managers of the hospitals and they were asked to state their opinions about the content, structure, and wording formation of the questionnaire. After applying the opinions of the experts, in a test run, the questionnaire reliability was confirmed through Cronbach's alpha as 0.935 .

The study participants included senior, middle and operating managers of hospitals of Tehran University of Medical Sciences $(\mathrm{N}=290)$. Due to the limited population, the questionnaire was distributed to all managers. Overall, 215 completed questionnaires were returned. Hospitals of Tehran University of Medical Science include: Imam Khomeini and Amir Alam Hospital complex, Tehran heart center and Children's medical center Hospitals, Dr Shariati, Sina, Rozbeh, Arash, Baharloo, Farabi, Razi, Bahrami, and Ziaeian Hospitals.
Identification and extraction of variables was performed using exploratory factor analysis. KolmogorovSmirnov test was used to test the normality of the components of the model; multi factor analysis was also applied to confirm the model while one sample t-test was used to respond to the hypotheses. Software including SSPS version 22 and Smart PLS version 2 were used.

\section{Results}

Respondents to the questionnaire included 144 females and 71 males. Their educational degree included academic level and lower, undergraduate, masters, and finally Ph.D and higher who were employed with positions including hospital director, nursing manager, supervisor, head of department, head of organization, and deputy director, respectively.

\subsection{Factor Analysis}

In order to conduct a factor analysis, the sample index of Kaiser-Meyer-Olkin was used while Bartlett's test was used to evaluate the correlation matrix. Given that the considered index (KMO) was equal to 0.902, and therefore the result of Bartlett's test was significant at a significance level of $95 \%$, implementation of factor analysis was allowed.

In order to extract a set of variables, factor analysis was performed for all 46-questions of the questionnaire. Common numbers of all questionnaires were greater than 0.5, which indicate their appropriateness. After implementation of Varimax rotation with Kaiser Normalization method, the main components were identified. All the main operating parameters were nine items and these nine factors covered $63.2 \%$ of the variance of total factors and explained it. The factors included: organizational culture, communication management, organizational commitment, organizational structure, employee satisfaction, empowerment, teamwork, and the management demonstration mission of the organization.

\subsection{Kolmogorov-Smirnov}

The results of Kolmogorov-Smirnov test revealed that the variables of organizational culture, communication management, organizational commitment, organizational structure, staff satisfaction, and empowerment had a normal distribution mean, while the variables of teamwork, change management, and mission of the organization had a normal average distribution. 
Table 1. Kolmogorov-Smirnov Test for Variables

\begin{tabular}{|c|c|c|c|}
\hline Variables & Z statistics & Significance Level & Result \\
\hline Organizational culture & 1.157 & 0.138 & Normal \\
\hline Communication management & 1.139 & 0.149 & Normal \\
\hline Organizational commitment & 1.164 & 0.133 & Normal \\
\hline Organizational structure & 1.233 & 0.096 & Normal \\
\hline Employee satisfaction & 1.161 & 0.135 & Normal \\
\hline Empowerment & 1.099 & 0.178 & Normal \\
\hline Teamwork & 1.944 & 0.001 & Not normal \\
\hline Change management & 1.747 & 0.004 & Not normal \\
\hline Mission & 2.694 & 0.000 & Not normal \\
\hline
\end{tabular}

\subsection{Confirmatory Factor Analysis}

Confirmatory factor analysis is one of the oldest statistical techniques, used to examine the relationship between latent variables (obtained factors) and observed variables (questions) and is indicative of the measurement model (25).

\subsection{Measurement Model}

Based on the results shown in Table 3, the Average Variance Extended (AVE) was higher than 0.5, in order to evaluate the convergence of all studied structures. According to the opinions of Fornell and Locker, a standard higher than 0.5 is appropriate for AVE. The results of validity evaluation obtained using Cronbach's alpha for all variables were higher than 0.7 and the combinational reliability was higher than 0.6 , which revealed good reliability and validity of the research questions.

\subsection{Goodness of Fit (GOF)}

According to Table 2, the compromise index between the quality of the structural model and the Measurement Model(GOF) was equal to 0.566, which was higher than 0.4, and indicated a perfect goodness fit of the model for a CRM. This research study was developed based on factor structure and good fit. This line represents the alignment of the questions with the theoretical constructs:

$$
\begin{aligned}
& G O F=\sqrt{\overline{\overline{A V E}}} \times \sqrt{\overline{\overline{R^{2}}}} \\
& \text { GOF }=0.722 \times 0.732=0.566
\end{aligned}
$$

\subsection{Estimation and Testing of the Model}

In Figure 1 the numbers or coefficients are divided to two categories. The first category, which is called the equations of the first order, clearly shows the relationship between latent and the obvious variables. The equations are called factor loadings. The second set of the measurement equations of the second order include the relationships between latent and obvious variables.

In order to analyze the structure of the questionnaire and discover the constituent elements of the structure, factor loadings were used. Load factor of 15 items (employee satisfaction) were less than 0.5 . It is necessary to delete this index from the model and the model should be reestimated regardless of this item. The loading factors of the remaining items were more than 0.5 , where the validity of the index can be confirmed. Therefore, it can be valid to measure the concepts at this stage.

\subsection{Model Coefficients Test}

Figure 3 shows the research model in a significant absolute value of the coefficients (t-value). In fact, in this model all the equations (first and second ordered loading factors) have been tested using the statistic t. According to this model, each loading factor was significant at the 95\% confidence level, according to the point that the amount of tstatistic was greater than +1.96 . The results showed that all loading factors were significant at the $95 \%$ confidence level.

\subsection{One Sample t-Test to Evaluate the Hypotheses}

The results of one-sample t test are shown in Table 4 . The mean responses to the independent variables were higher than 3. The critical value of one sequence test in the alpha level of 0.05 was equal to 1.645. On the other hand, the t-statistic was greater than the critical value of a sequence, and it can be said that $95 \%$ of the research hypothesis was confirmed.

Organizational culture, mission, organizational structure, management of communication, organizational commitment, employee satisfaction, teamwork, empowerment and change management influences the CRM in 
Table 2. Items Validity and Reliability

\begin{tabular}{|c|c|c|c|c|c|c|c|}
\hline Latent Variables & AVE & CR & $\mathbf{R}^{2}$ & Cronbach's alpha & Mean Square of AVE & Mean Square of $R^{2}$ & GOF \\
\hline Empowerment & 0.551 & 0.859 & 0.525 & 0.794 & \multirow{10}{*}{0.772} & \multirow{10}{*}{0.732} & \multirow{10}{*}{0.566} \\
\hline Mission & 0.755 & 0.861 & 0.345 & 0.777 & & & \\
\hline $\begin{array}{l}\begin{array}{l}\text { Employee } \\
\text { satisfaction }\end{array} \\
\end{array}$ & 0.564 & 0.885 & 0.644 & 0.842 & & & \\
\hline $\begin{array}{l}\text { Organizational } \\
\text { culture }\end{array}$ & 0.573 & 0.862 & 0.611 & 0.812 & & & \\
\hline $\begin{array}{l}\text { Communication } \\
\text { management }\end{array}$ & 0.581 & 0.866 & 0.611 & 0.82 & & & \\
\hline $\begin{array}{l}\text { Organizational } \\
\text { commitment }\end{array}$ & 0.529 & 0.87 & 0.606 & 0.822 & & & \\
\hline $\begin{array}{l}\text { Change } \\
\text { management }\end{array}$ & 0.563 & 0.794 & 0.476 & 0.716 & & & \\
\hline $\begin{array}{l}\text { Organizational } \\
\text { structure }\end{array}$ & 0.572 & 0.841 & 0.501 & 0.776 & & & \\
\hline Teamwork & 0.685 & 0.867 & 0.506 & 0.769 & & & \\
\hline $\begin{array}{l}\text { Customer } \\
\text { relationship } \\
\text { management }\end{array}$ & 0.693 & 0.949 & 0 & 0.945 & & & \\
\hline
\end{tabular}

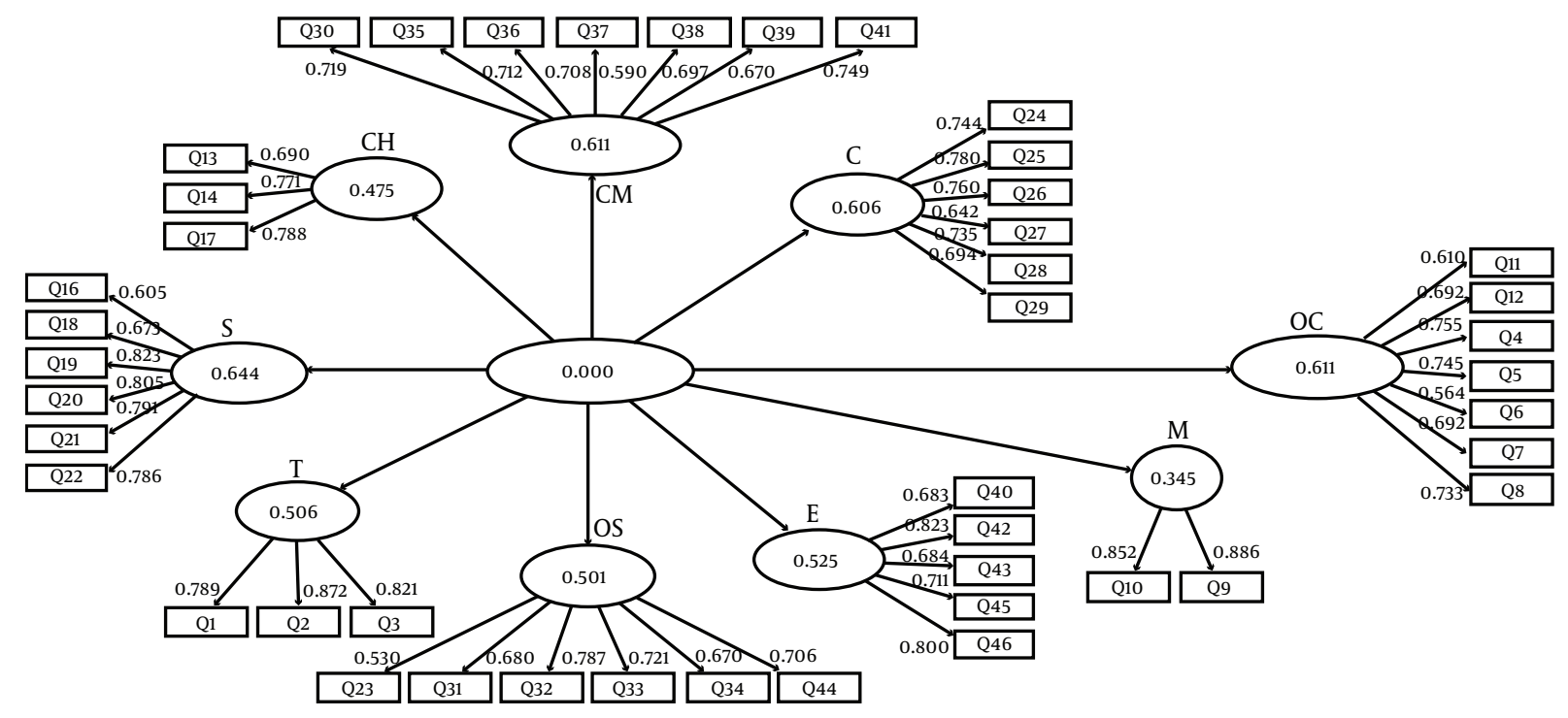

Figure 1. The Research Model for Estimation of the Standard

teaching hospitals of Tehran University of Medical Sciences.

\section{Discussion}

Based on the pattern extracted from the most important factors, it can be suggested to include organizational culture, communication management, organizational commitment, organizational structure, staff satis- faction, empowerment, teamwork, change management and mission.

Nadler believes that organizational culture that has a high level of the index change has the ability to represent an adoption strategy in order to achieve the changing needs of its own (26). Habidin performed a research on the association between relationship management with customer, development of service quality, and organizational performance development in Malaysia's healthcare indus- 
Table 3. The Results of the Loading Factors

\begin{tabular}{|c|c|c|c|}
\hline Factors & The Corresponding Questionin the Questionnaire & Items & Load Factors \\
\hline \multirow{7}{*}{ 1. Organizational Culture $=\mathrm{OC}$} & 6 & Creating change & 0.564 \\
\hline & 12 & Strategy change & 0.692 \\
\hline & 7 & Customer focus & 0.692 \\
\hline & 8 & Organizational learning & 0.733 \\
\hline & 11 & Vision & 0.610 \\
\hline & 4 & Agreement & 0.755 \\
\hline & 5 & Coordination and integration & 0.745 \\
\hline \multirow{7}{*}{ 2. Communication Management $=\mathrm{CM}$} & 36 & According to the patient when speaking & 0.708 \\
\hline & 38 & Provide patient education & 0.697 \\
\hline & 35 & Respectful behavior with patients & 0.712 \\
\hline & 39 & Dress code & 0.670 \\
\hline & 37 & Read and study & 0.590 \\
\hline & 41 & Say & 0.749 \\
\hline & 30 & Training & 0.719 \\
\hline \multirow{6}{*}{ 3. Organizational Commitment $=\mathrm{C}$} & 25 & Interest in continue work & 0.780 \\
\hline & 26 & Interest in solving problems & 0.760 \\
\hline & 29 & Commitment despite better work market & 0.694 \\
\hline & 28 & Moral values & 0.735 \\
\hline & 24 & Proportionality of jobs and career & 0.744 \\
\hline & 27 & Stay on the job & 0.642 \\
\hline \multirow{6}{*}{ 4. Organizational structure $=O S$} & 32 & Decision making & 0.787 \\
\hline & 31 & Guideline & 0.680 \\
\hline & 34 & Levels of hierarchy & 0.670 \\
\hline & 44 & On the Job training & 0.706 \\
\hline & 23 & Work repetitious & 0.530 \\
\hline & 33 & Coordination between units & 0.721 \\
\hline \multirow{7}{*}{ 5. Employee satisfaction $=S$} & 21 & Communications & 0.791 \\
\hline & 19 & Payment based on the importance of the work & 0.823 \\
\hline & 22 & Job enrichment & 0.786 \\
\hline & 16 & Leadership style & 0.605 \\
\hline & 20 & Promotion based on performance & 0.805 \\
\hline & 18 & Workplace & 0.673 \\
\hline & 15 & Systems and methods of work & 0.459 \\
\hline \multirow{5}{*}{ 6. Empowerment $=\mathrm{E}$} & 42 & Authorize & 0.823 \\
\hline & 43 & Autonomous work group & 0.684 \\
\hline & 46 & Autonomy in job & 0.800 \\
\hline & 40 & Proper design work & 0.683 \\
\hline & 45 & Task significance & 0.711 \\
\hline \multirow{3}{*}{ 7. Team work $=T$} & 1 & Empowerment programs & 0.789 \\
\hline & 2 & Team orientation & 0.872 \\
\hline & 3 & Capability development & 0.821 \\
\hline \multirow{3}{*}{ 8. Change management $=\mathrm{CH}$} & 14 & Change core values & 0.771 \\
\hline & 13 & Flexibility in the organizational structure & 0.691 \\
\hline & 17 & Change in how to serve & 0.786 \\
\hline \multirow{2}{*}{ 9. Missin = M } & 10 & Goals and objectives & 0.852 \\
\hline & 9 & Specific objectives & 0.886 \\
\hline
\end{tabular}

try. In this research, organizational culture by developing organizational readiness for change and agreement on the use of information technology can be aligned with the di- mension of agreement and change strategy in the present research (17).

The most important feature of organizational culture 


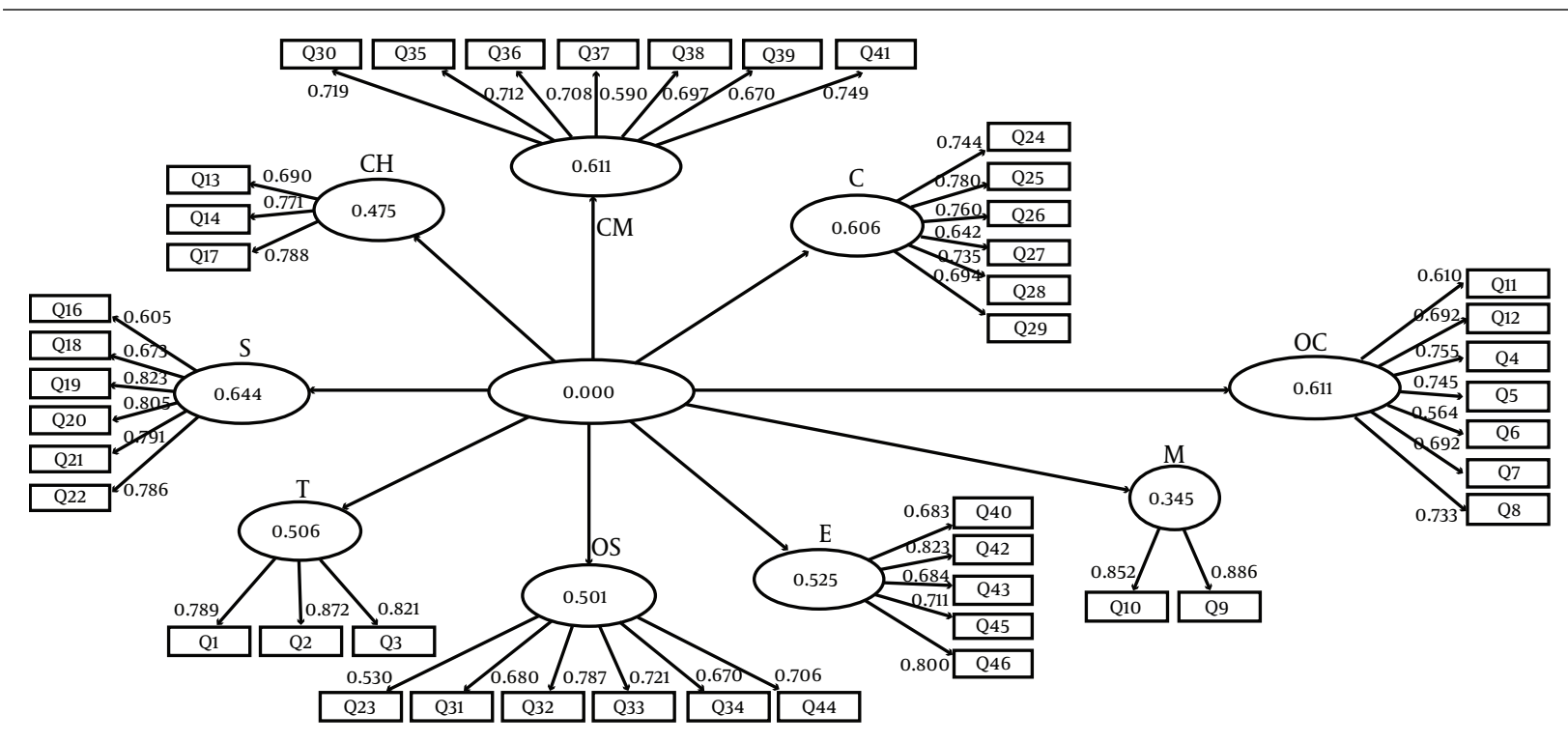

Figure 2. The Modified Version (removing the questions with the loading factors less than 0.5) in the Condition of the Estimated Standardized Coefficients

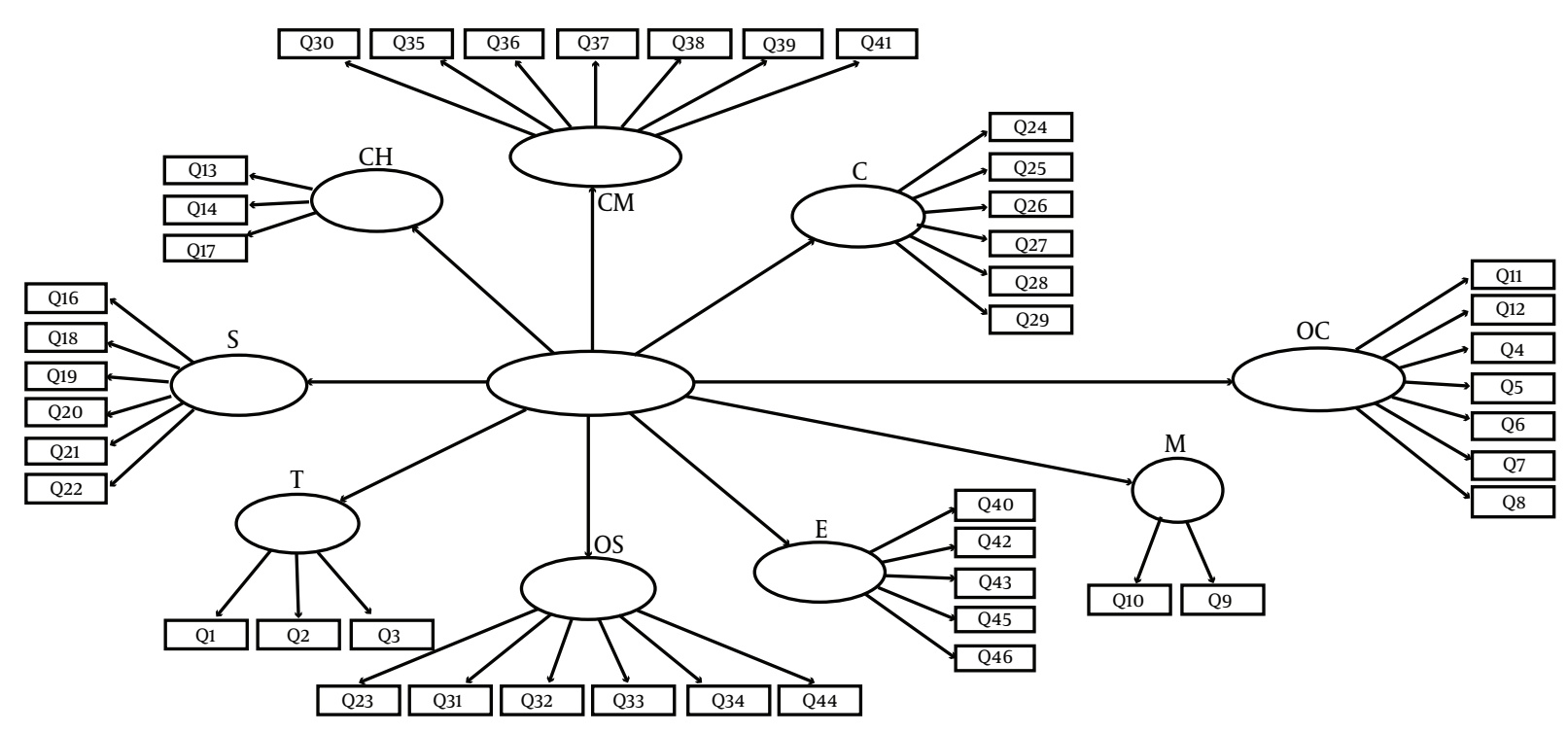

Figure 3. Modified Model in the Significant State (t-value)

was its mission; therefore, in order to investigate the behavior of members of an organization, awareness of the organizational culture is a fundamental step. The results of the present study demonstrated that the relationship between mission and CRM, in Hospitals of Tehran Medical Sciences was positive. These results were in accordance with the study of Saadati and colleagues, who examined the organizational culture of the hospitals (organization) of Mashhad and Neishabur, based on the denison pattern in the organization's mission dimension. In other words, there is a common and clear vision for the organization to reach customer orientation (27).

Implementation of CRM process requires a change in the organization, structure and business processes (8). In Azizzadeh's research and his colleagues in Ansar Bank, it was found that there was a positive relationship between the dimensions of organizational structure (formalization, complexity and concentration) and CRM aspects 
Table 4. The Results of t-Test

\begin{tabular}{|c|c|c|c|c|c|c|}
\hline Independent Variable & Dependent Variable & Mean & SD & Statistic t & Sign & Result \\
\hline Organizational culture & \multirow{9}{*}{ CRM } & 3.81 & 0.621 & 19.12 & 0 & No rejected \\
\hline Mission & & 3.958 & 0.717 & 19.585 & 0 & No rejected \\
\hline Organizational structure & & 3.737 & 0.616 & 17.545 & 0 & No rejected \\
\hline $\begin{array}{l}\text { Communication } \\
\text { management }\end{array}$ & & 4.19 & 0.551 & 31.656 & 0 & No rejected \\
\hline $\begin{array}{l}\text { Organizational } \\
\text { commitment }\end{array}$ & & 3.95 & 0.647 & 21.547 & 0 & No rejected \\
\hline Employee satisfaction & & 4.065 & 0.613 & 25.447 & 0 & No rejected \\
\hline Teamwork & & 3.904 & 0.747 & 17.731 & 0 & No rejected \\
\hline Empowerment & & 3.856 & 0.658 & 19.092 & 0 & No rejected \\
\hline Change management & & 3.805 & 0.655 & 18.039 & 0 & No rejected \\
\hline
\end{tabular}

that was in accordance with the results of the present study in the context of a codified guideline and a focus decisionmaking (20). On the other hand, it was not consistent with Orina's research entitled "the analysis of organizational factors influencing the successful implementation of CRM in the banking system in the organizational structure" (19).

Complexity of communications, forced the authors of this article to gain knowledge and skills necessary to communicate and coordinate with the environment (28). Yaghoubi in a research on tasks and effects of the CRM in selected hospitals of Isfahan emphasized that for creating a powerful organization it is necessary to communicate with the customers, and the interaction with customers is amongst the tasks of the CRM, which was consistent with the following item of the present study; 'learning how to interact with the members' (29).

Commitment is considered as a human attitude (30). The results of Lacej (2015) revealed that organizational commitment influences the customer with an adequate level of performance, and also the organizational commitment in the values, attitudes and beliefs dimensions are the basis axes for developing good relationships with the customer, which is consistent with the results of the present study in terms of moral values (norms) (31).

Happy employees are more likely to be more fruitful (32). Results of Laguador in 2014 showed that staff satisfaction influences organizational performance and customer satisfaction in the aspects of learning and development, reward and recognition, leadership and workplace (33), which was consistent with the results of this study, regarding leadership style, work environment, and pay to staff. Furthermore, these results were consistent with the results of Orina (2014) for the successful implementation of customer relationship management in the banking sys- tem in Burma, regarding the employee satisfaction dimension (19).

Enabling include empowering the skills of the employees and building confident about themselves and work towards the effectiveness of the organization's activities (34). Results of an empowerment research on employees and customers of the Sepah Bank showed that in order to have efficient and effective organizations, the managers must have management capabilities, skills, experience and social intelligence. Enhanced capabilities are possible via courses training, participation in seminars and conferences (18), which is consistent with the present research for implementation of empowerment programs and strength of capabilities.

Irannejhad and colleagues found that there is independence, self-organized, meaningful of jobs and confidence with the CRM (35), which was consistent with the results of this research on significant aspects of the job, autonomy and self-organization.

The business world and its relations are rapidly changing and becoming more complex, thus organizations that will be more successful in the future are those who manage their goals and ideas into this direction. The results of Shum et al. on the commitment of the staff to perform the changes at different levels of the organization led to create a customer-oriented culture and to change the staffs and processes (36). In this study, the emotional commitment of individuals with organizational changes with the shared values and flexibility in the present study corresponded to the structure of the organization.

The successful implementation of CRM strategy requires employees, technology and processes importantly, but human resources have integral roles in building customer relationships (11). In order to have a customer- 
oriented institution, the organization's culture should be changed. More ever, commitment to the customer orientation should be a pivotal and vital belief at the high-level of an organization. Processes and systems of the organization should be changed (13). Hence, today, health care organizations require CRM standards more than other industries (16). Based on the results of this research, implementing customer-oriented institutions as a high major value and belief in the organization, empowering employees through job re-engineering and developing skills, responsibility, enhancing communication skills through education, promoting employees based on performance and performance-based payment can be effective in the hospitals of medical science university.

\section{Acknowledgments}

The authors of this article, which was extracted from a doctoral thesis, state their deep gratitude to all the managers of Medical Sciences, Tehran hospitals, who had a sincere cooperation during the study.

\section{References}

1. Elahi S, Hedari B. Customer Relationship Management. t ed. Tehran: Business Publishing Company; 2012. p. 136.

2. Alam TA, Mohammad RA. Trend in Production and Operation Management Advanced: With The Approch of Value Chain Management,Lean Mnufacturing and Customer Reationship Mnagement. Tehran: Business Publishing Company; 2010.

3. Schurter T, Towers S. Mnagement Expectation Customer. Megan Kiffer Pr. 2006.

4. Thompson B. Successful CRM: Turning customer loyalty into profitability. RighNow Technologies Publication. 2004.

5. Liou JJH. A novel decision rules approach for customer relationship management of the airline market. Expert Systems with Applications. 2009;36(3):4374-81.

6. Abbasi MR, Torkamani M. The Theoretical Model of Customer Relationship Mnagement. Business Review. 2010 ;41:19-34.

7. Noe RA, Hollenbeck JR, Gerhart B, Wright PM. Human Resource Management: Gaining A Com-petive Advantage,. McGraw-Hil; 2000.

8. Agarwal A, Harding DP, Schumacher JR. Organizing for CRM.. 3. McKinsey Quarterly.; 2004.

9. Sin LY, Tse AC, Yim FH. CRM: conceptualization and scale development. European Journal of marketing. 2005;39(11/12):1264-90.

10. Nykamp M. The customer differential: The complete guide to implementing customer relationship management. Amacom; 2001.

11. McGovern T, Panaro J. The human side of customer relationship management. Benefits Quarterly. 2004;20(3):26.

12. Christopher M, Payne A, Ballantyne D. Relationship marketing: bringing quality customer service and marketing together. 1991

13. Cox G. Customer focus-a commercial imperative. Managing Service Quality: An International Journal. 1997;7(1):27-30. doi: 10.1108/09604529710158265.

14. Mohammd BT. Customer-centric and customer behavioral techniques. Tehran: Site; 2014. p. 19.

15. Sadegh Tbarizi J, Zare Gavkani V, Farahbakhash M. Patient and community participation. Tabriz: Alvin; 2014.
16. Rahim Nia F, Zeynvand Lorestani H, Feiz Mohammadi S. Factors Affecting Adoption of Customer Relationship Management System in Mashhad Hospitals. Health Inf Manage. 2014;11(1):88-98.

17. Habidin NF, Ali N, Khaidirali NA, Shazali NA, Jusoh O. Relationship between customer relationship management, service qualityimprovement and organizational performance in malaysian healthcare industry. International Journal of Innovation and Scientific Research. 2015;14(2):291-302.

18. Vazifehdoost H, Toluei F, Alizadeh T, Hajlou H. Investigation of relationship between customer relationship management dimensions and organizational productivity. Mediterranean J Soc. 2014;5(23):27018

19. Orina TH. Analysis of institutional factors affecting successful implementation of customer relationship management in banking system of brahema city.. Int J Bus Econ Manag. 2014;1(2):90-9.

20. Azizzadeh F, Bahrami H, Sfestani RS. The relations of organization structure and customer relationship management in Ansar Bank of Urmia. J Data Envelopment Analysis Decision Sci. 2014;2014:1-10.

21. Yaghoubi M, Rahi F, Asgari H, Javadi M. Customer Relationship Management Model by Using the Structural Equation Model in Hospitals of Isfahan University of Medical Sciences.. Health Infomation Management. 2014;10(7):1052-957.

22. Akgun AE, Imamoglu S. Z. , Kocoglu I. , Ince H. , Keskin H. . Bridging Organizational Learning Capability and Firm Performance through Customer Relationship Management. Procedia Soc Behav Sci. 2014;150:531-40.

23. Gbadeyan RA. Customer Relationship Management and Hospital Service Quality in Nigeria. African Research Review. 2010;4(2):168-84.

24. Tafti MHA. Analysis of factors affecting implementation of customer relationship management systems. Information resources management association. $2002 ; 4$.

25. Byrne BM. Structural equation modeling with EQS and EQS/Windows: Basic concepts, applications, and programming. Sage; 1994.

26. Nadler DA. Champions of change: How CEOs and their companies are mastering the skills of radical change. Sanfrancisco,CA: Jossey-Bass; 1997.

27. Saadati A, Bidgili M, Saadati SM, Ghodsi A, Salahshor A, Kavoosi A. Evaluation Of hospital culture(organization)on the pattern of Denison.. Qurtery J Nurs Manag. 2014;3(4):53-9.

28. Joseph A. Group Process:An Introduction to Group Dynamic. Palo Alto, CA: National Press; 1963.

29. Yaghoubi M, Rahi F, Bahadori MK. Assessment tasks of customer relationship management in selected hospitals of Isfahan city. Health Syst Res. 2015;11(1):119-31.

30. Vedady A, Rezaeezadeh M, Najafi H. Organizational commitment and employee turnover. 9. Business Management; 2011.

31. Lacej A, Kalaj EH. The Effect of Consumer Relationship Management on Satisfaction and Loyalty: A Focus on Albanian Tour Operator Business. Mediterranean J Soc Sci. 2015;6(2 S1):635.

32. Judge TA, Thoresen CJ, Bono JE, Patton GK. The job satisfaction-job performance relationship: a qualitative and quantitative review. Psychol Bull. 2001;127(3):376-407. [PubMed: 11393302].

33. Laguador JM, Castro EAD, L MP. Employees' Organizational Satisfaction and Its Relationship with Customer Satisfaction Measurement of an Asian Academic Institution. Quarterly Journal of Business Studies. 2014;1(3):83-93.

34. Monavvariyan A, Ghorbani M, Sharifi M. Based on Denison organizational culture model. Shiraz: Shiraz University Publication Center; 2008.

35. Irannejhad $\mathrm{N}$, Yadollahi M. The relationship between empowerment of employees and customer relationship management (based on whetten and cameron) sepah bank branches in kerman province, national conference on the dynamics of management, economic development and financial management. Shiraz,Iran:: Pendar Andish Rahpoy company; .; 2014. 
36. Shum P, Bove L, Auh S. Employees' affective commitment to change: The key to successful CRM implementation. Eur J Mark.
2008;42(11/12):1346-71. 